ARTICLE

https://doi.org/10.1038/s41467-019-14271-2

\title{
Insulated conjugated bimetallopolymer with sigmoidal response by dual self-controlling system as a biomimetic material
}

Hiroshi Masai ${ }^{1}$, Takuya Yokoyama ${ }^{2}$, Hiromichi V. Miyagishi (1) ${ }^{1}$, Maning Liu ${ }^{3}$, Yasuhiro Tachibana (D) ${ }^{3}$, Tetsuaki Fujihara², Yasushi Tsuji ${ }^{2} \&$ Jun Terao [i ${ }^{1 *}$

Biological systems are known to spontaneously adjust the functioning of neurotransmitters, ion channels, and the immune system, being promoted or regulated through allosteric effects or inhibitors, affording non-linear responses to external stimuli. Here we report that an insulated conjugated bimetallopolymer, in which $\mathrm{Ru}(\mathrm{II})$ and $\mathrm{Pt}(\mathrm{II})$ complexes are mutually connected with insulated conjugations, exhibits phosphorescence in response to $\mathrm{CO}$ gas. The net profile corresponds to a sigmoidal response with a dual self-controlling system, where drastic changes were exhibited at two threshold concentrations. The first threshold for activation of the system is triggered by the depolymerization of the non-radiative conjugated polymer to luminescent monomers, while the second one for regulation is triggered by the switch in the rate-determining step of the Ru complex. Such a molecular design with cooperative multiple transition metals would provide routes for the development of higherordered artificial molecular systems bearing bioinspired responses with autonomous modulation.

\footnotetext{
${ }^{1}$ Department of Basic Science, Graduate School of Arts and Sciences, The University of Tokyo, Tokyo 153-8902, Japan. ${ }^{2}$ Department of Energy and Hydrocarbon Chemistry, Graduate School of Engineering, Kyoto University, Kyoto 615-8510, Japan. ${ }^{3}$ School of Engineering, RMIT University, Bundoora, Victoria 3083, Australia. *email: cterao@mail.ecc.u-tokyo.ac.jp
} 
$\mathrm{N}$ atural systems can autonomously control their responses to promote and regulate various pathways, depending on the intensities of external stimuli. The controlling system plays an important role as a modulator in the relay of biological information and prevents needless responses to trivial and excessive inputs (Fig. 1a) ${ }^{1}$. The natural self-controlling systems, i.e., selfactivating and self-regulatory systems are attributed to the allosteric effects and cascade mechanisms, including reversible and irreversible reactions among multiple proteins and bioactive compounds ${ }^{2,3}$. The sigmoidal responses with multiple thresholds for inputs afford stable biological activities in the surrounding environment. For example, self-activating thresholds ignore weak stimuli and enhance the sensitivity above the thresholds, while selfregulatory thresholds suppress excess output signals toward the next system in the information relay. Such sophisticated mechanisms are essential in the functioning of neurotransmitters, immune systems, ion channels, and transport systems ${ }^{4-6}$. Several studies have proposed the molecular designs of biomimetic materials as sensors ${ }^{7-10}$, catalytic systems ${ }^{11,12}$, and machines transporting materials ${ }^{13-15}$. However, to the best of our knowledge, no artificial compound has been developed to mimic a dual self-controlling system that involves both self-activation and self-regulation to date. Mimicking such self-controlling systems has been regarded as a challenge, since such systems would provide autonomous modulations into diverse artificial materials and systems, such as sensors, catalysts, and machines, without any human control.

As opposed to reversible reactions, chemical responses based on irreversible reactions have been utilized for memorizing the detection and for the directional transfer of information ${ }^{16}$. However, the responses (e.g., emission intensity) increase monotonically only when the target concentration [T] is not in excess (Fig. 1b). The artificial incorporation of multiple modulations into the irreversible reactions would be complex, despite their potential applications in the aforementioned biomimetics. In order to achieve a dual selfcontrolling system for $[\mathrm{T}]$ in irreversible reactions (Fig. 1c), herein, two strategies were applied on a single molecular component. The first strategy was a polymer to monomer conversion for self- activation at a low target concentration (Fig. 1d). The random depolymerization from polymer to monomer would initially afford oligomers and then monomers around a threshold concentration $\left(c_{1}\right)$, depending on the progress of the reaction. Accordingly, depolymerization to monomers should ultimately lead to the attainment of a threshold monomer concentration, which would correspond to the threshold concentration for activation via a monomer-induced output in a chemical reaction. The second strategy was targeted at self-regulation at high target concentrations, via a switch in the rate-determining step in reactions composed of two elementary steps, as observed in biological systems (Fig. 1e). The reaction was designed in such a way that the target was sensed after the intramolecular removal of the inhibitors, which prevented the substrates from reacting with the target. This was carried out to ensure that the dependence of the total reaction rate $\left(V_{\text {total }}\right)$ on $[\mathrm{T}]$ could be switched at the threshold concentration $\left(c_{2}\right)$, because the first reaction rate $\left(v_{1}\right)$ was independent of [T], while the other $\left(v_{2}\right)$ was dependent on it. Accordingly, the extent of the reaction would be regulated above $c_{2}$ owing to the switch in the rate-determining step from $v_{2}$ to $v_{1}$. The compatibility of the two strategies on a single chemical compound with suitable concentration thresholds would afford unprecedented artificial sigmoidal responses in the aforementioned biomimetics with dual self-controlling systems. In this study, we demonstrate the artificial dual self-controlling responses using single polymer, which is composed of two transition metals and cyclodextrin-based insulated conjugation. The cooperative multiple transition metals provide excellent biomimetic response at two threshold concentrations of CO.

\section{Results}

Design for dual self-controlling system. Herein, a molecular design for the artificial dual self-controlling system, comprising selfactivation and self-regulation, is proposed. We utilize the luminescence from the system as the output signal, specifically focusing on the phosphorescence of transition metal complexes. This is because the large stokes shift in their emission is largely unaffected by the excited light, which increases the signal-to-noise ratio ${ }^{17-19}$. a

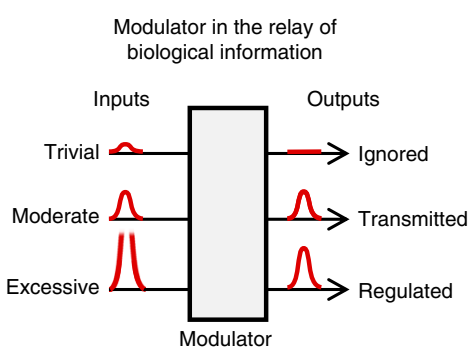

d

Self-activation strategy via monomer-induced output

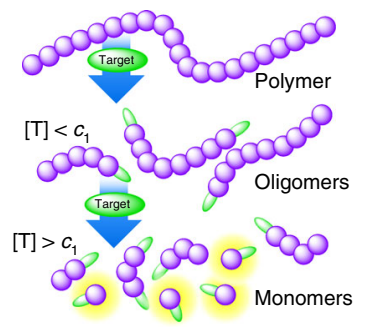

b

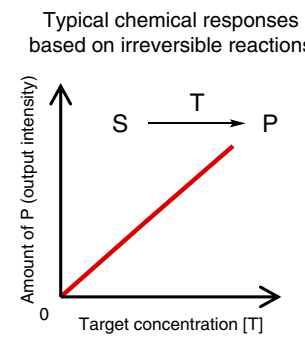

C

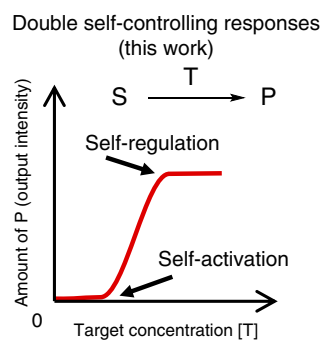

e

Self-regulation strategy via switch in the rate-determining step

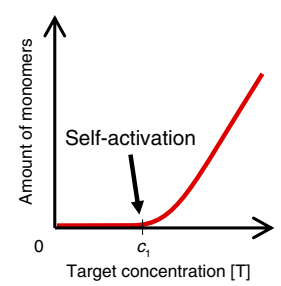

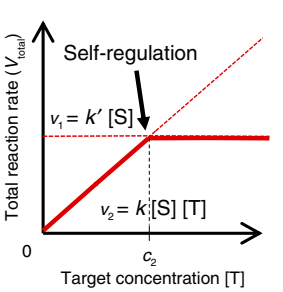

Fig. 1 Conceptual illustration of sigmoidal response by dual self-controlling system. a Modulator in the relay of biological information. $\mathbf{b}$ Chemical responses for the target concentration in conventional responses. c Dual self-controlling responses (this work) (S: substrate, $T$ : target, and P: product). d Schematic strategies for self-activation based on random depolymerization. e Self-regulation based on a switch in the rate-determining step ( $c_{1}$ and $c_{2}$ are the threshold concentrations). 


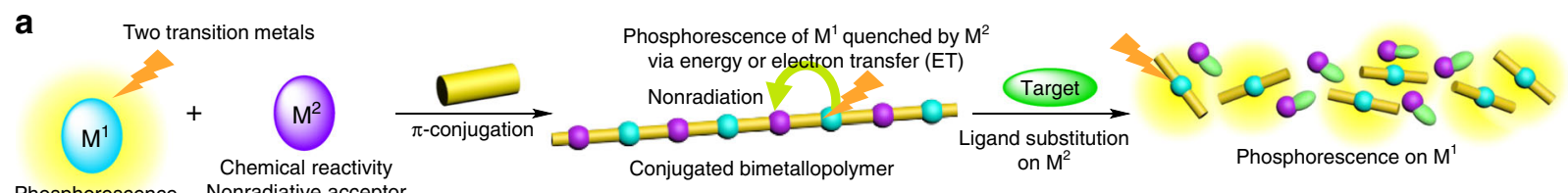

Phosphorescence Nonradiative acceptor

on $\mathrm{M}^{2} \quad$ Phosphorescence on $\mathrm{M}^{1}$

b

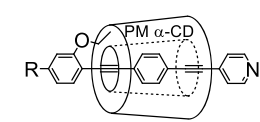

1: $\mathrm{R}=\mathrm{I}$

2: $\mathrm{R}=\mathrm{TMSC} \equiv \mathrm{C} \xi$

3: $\mathrm{R}=\mathrm{HC} \equiv \mathrm{C} \frac{\xi}{3}$

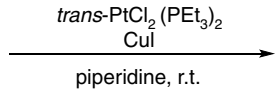

$(70 \%)$

$\mathrm{TMS}=, \mathrm{PdCl}_{2}\left(\mathrm{PPh}_{3}\right)_{2}, \mathrm{Cul}$

piperidine, r.t. (quant.)

$\mathrm{K}_{2} \mathrm{CO}_{3}, \mathrm{MeOH}$, r.t. (93\%)

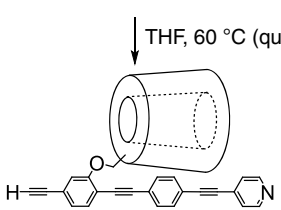

3'

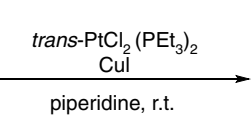

$(47 \%)$
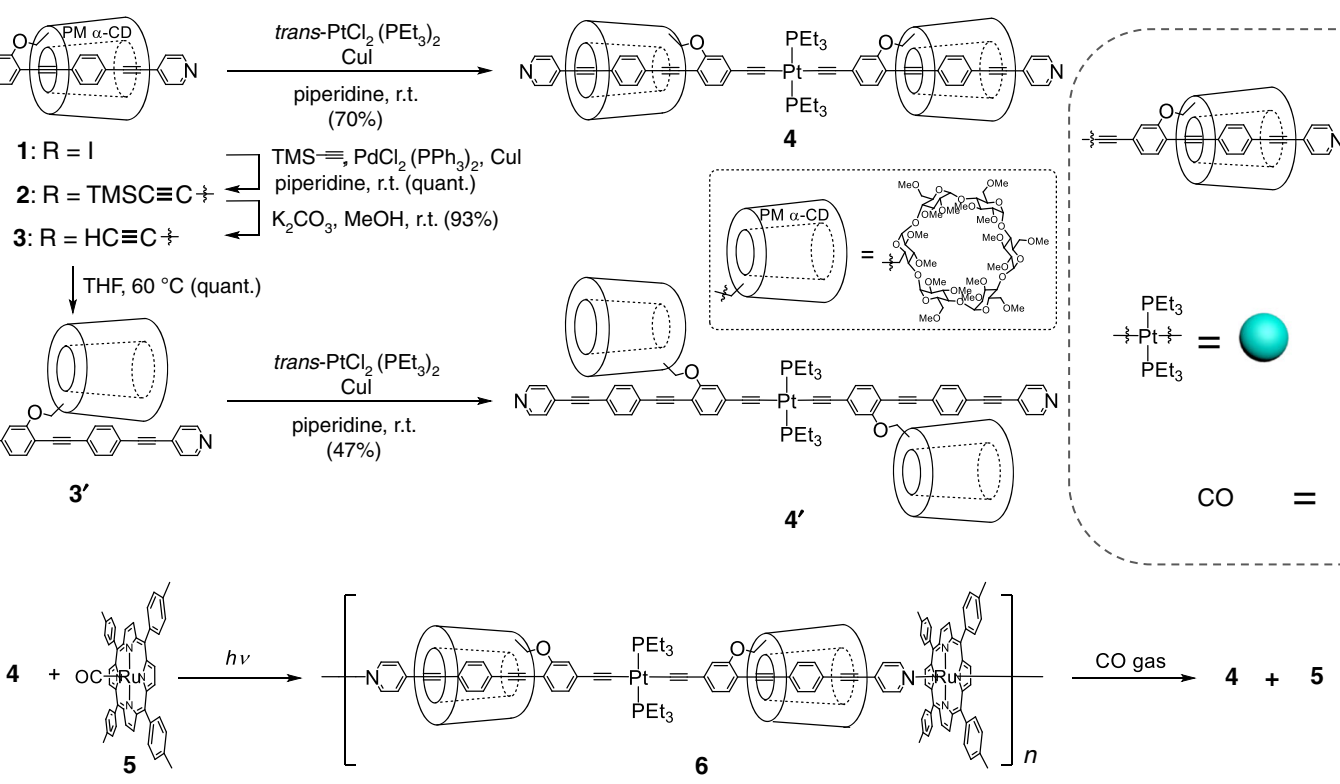

4

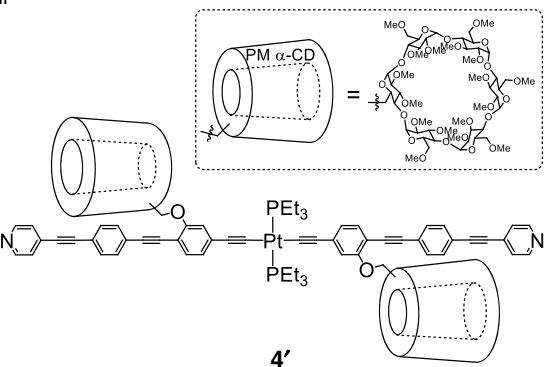

$4^{\prime}$

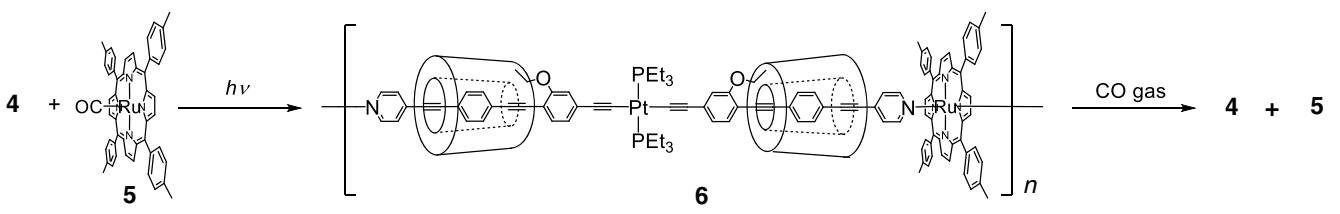

6

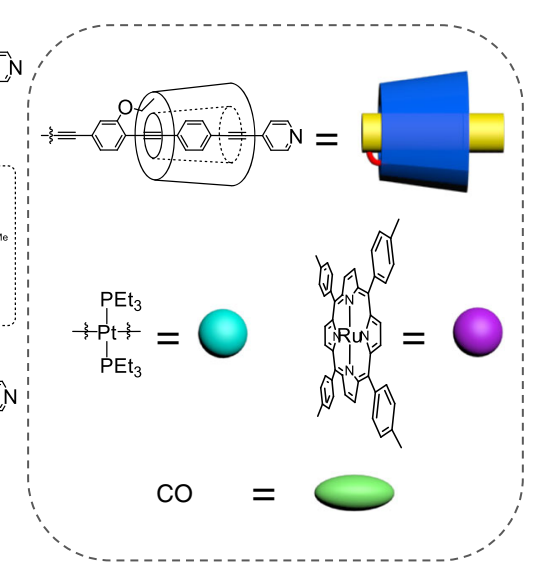

Fig. 2 Synthesis and response of bimetallopolymer. a Illustrations of the phosphorescence sensing mechanism based on a conjugated bimetallopolymer with two transition metals. b The synthetic route to the insulated conjugated bimetallopolymer $\mathbf{6}$.

To incorporate the dual responses into the phosphorescence output, a second transition metal was introduced. Accordingly, two transition metals, one capable of phosphorescence $\left(\mathrm{M}^{1}\right)$, and the other behaving as a nonradiative acceptor with chemical reactivity $\left(\mathrm{M}^{2}\right)$, were mutually connected with organic moieties to form a conjugated bimetallopolymer (Fig. 2a). In the polymer and oligomer, the excited state of $\mathrm{M}^{1}$ was thermally quenched by $\mathrm{M}^{2}$ via energy or electron transfer (ET) ${ }^{20-23}$. The ligand substitution on $\mathrm{M}^{2}$ with the target compounds resulted in depolymerization of the bimetallopolymer to phosphorescent monomers, $\mathrm{M}^{1}$, and target ligand bound- $\mathrm{M}^{2}$, thereby leading to monomer-based phosphorescence upon depolymerization (Fig. 1d). Here, $\mathrm{M}^{1}$ and $\mathrm{M}^{2}$ correspond to $\mathrm{Pt}(\mathrm{II})$-acetylide and $\mathrm{Ru}(\mathrm{II})$ porphyrin-pyridyl moieties; that is, $\mathrm{Pt}$ (II)-acetylide functioned as the phosphorescent site ${ }^{24}$, while the $\mathrm{Ru}$ (II) porphyrin-pyridyl moieties behaved as acceptors with carbon monoxide (CO) reactivity ${ }^{25}$. As outlined in Fig. 1e, a hexacoordinated $\mathrm{Ru}$ complex allows switching of the target concentration dependence at the threshold concentration because the ligand substitution was proposed to follow a dissociation mechanism involving two elementary reactions, the reaction rate of one of which depended on the concentration of the target molecule ${ }^{26}$. Precisely, the biomimetic bimetallopolymer should respond to the concentration of the target gas, with the optical responses being separately activated and regulated at two threshold concentrations.

Synthesis and optical properties of insulated conjugated bimetallopolymer 6 . Figure $2 \mathrm{~b}$ shows the synthetic route to the abovementioned conjugated bimetallopolymer containing an insulated structure, where the $\mathrm{Pt}(\mathrm{II})$ and $\mathrm{Ru}(\mathrm{II})$ complexes were polymerized with oligo(phenylene ethynylene) (OPE) backbones and insulated by permethylated $\alpha$-cyclodextrins (PM $\alpha$-CDs $)^{27,28}$. According to our previous studies, the incorporation of rotaxane structures into conjugated metallopolymers enhanced the phosphorescence intensity ${ }^{24}$, thereby improving the output further. Precursor 1 was prepared in seven steps from 6-O-monotosyl PM $a-C D$, according to a previous report ${ }^{27}$. Compound 1 was alkynylated via a Sonogashira coupling reaction at ambient temperature to retain the insulated structure. Subsequent deprotection to remove the silyl group afforded the target insulated monomer $\mathbf{3}$, where the insulated structure of $\mathbf{3}$ was kinetically stabilized by the terminal alkynyl group. The corresponding uninsulated monomer $\mathbf{3}^{\prime}$ was obtained by heating a solution of $\mathbf{3}$ in the hydrophobic solvent, tetrahydrofuran, which was unfavorable for the insulation ${ }^{29}$. A copper-catalyzed metalation reaction at room temperature between 3 and trans- $\left[\mathrm{PtCl}_{2}\left(\mathrm{PEt}_{3}\right)_{2}\right]$ formed a 2:1 insulated Pt-acetylide complex 4 (ref. ${ }^{30}$ ), and the corresponding uninsulated complex $4^{\prime}$ was also obtained under the same reaction condition from $3^{\prime}$. The ${ }^{1} \mathrm{H}$ NMR spectrum of 4 displayed low-field shift for the insulated aryl groups and highfield shift for the pyridyl groups, as compared with the corresponding groups of $\mathbf{4}^{\prime}$ (Supplementary Fig. 1). The relative lowfield shift occurred because of the supramolecular interaction between the PM $\alpha$-CDs and the phenyl groups, while the highfield shift occurred because of the neighboring effect between the PM $\alpha$-CDs and the pyridyl groups (Supplementary Fig. 2) ${ }^{31}$. In addition, the ${ }^{31} \mathrm{P}$ NMR spectrum suggested that both the insulated and uninsulated Pt complexes adopted the trans-Pt-diacetylide conformation ${ }^{32}$. The clear vibration bands in deoxygenated toluene solutions were suggestive of $\pi-\pi^{*}$ phosphorescence, which was a characteristic luminescence of Pt-acetylide complexes (Fig. 3a). The lifetime of the excited species was $\sim 1 \mu \mathrm{s}$, which was determined by transition absorption decay (Supplementary Figs. 6a and 7a ${ }^{20}$. While the OPE conjugation in $\mathbf{4}$ was twisted to slightly shorten the effective conjugation length (4: $556 \mathrm{~nm}, 4^{\prime}: 564 \mathrm{~nm}$ ), insulation by the cyclic PM $\alpha$-CDs protected the OPE conjugation from the thermal fluctuations ${ }^{24,33}$. The phosphorescence quantum yield of $4\left(\Phi_{\mathrm{PL}}=26 \%\right)$ in toluene 

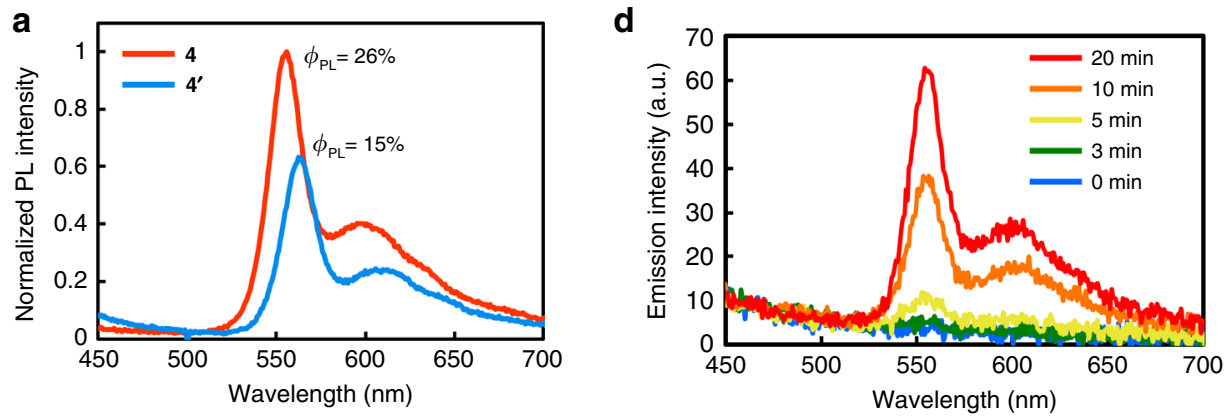

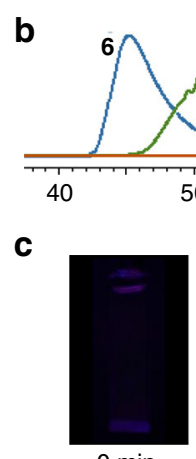

$0 \min$

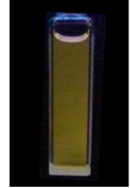

$5 \min$

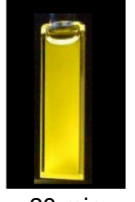

$20 \min$
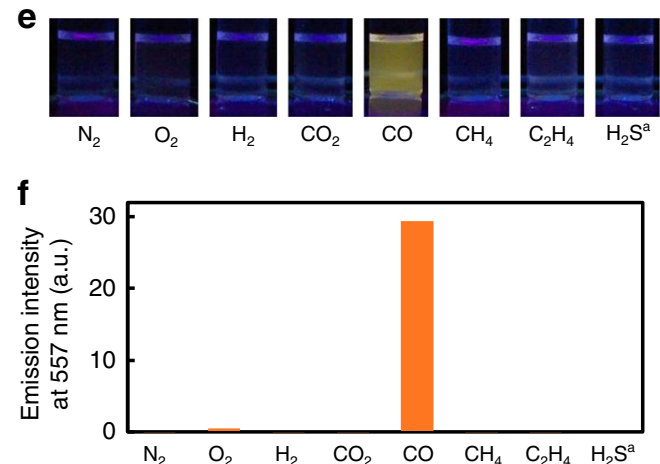

Fig. 3 Optical analyses of Pt complexes and bimetallopolymer. a Emission spectra of Pt complexes $\mathbf{4}$ and $\mathbf{4}$ ' in deoxygenated toluene (concentration: $10^{-5} \mathrm{M}$ ). The spectra were corrected to the same number of photons absorbed at the excitation wavelength. b SEC profiles at various time points (blue: $0 \mathrm{~min}$, green: $5 \mathrm{~min}$, and orange: $20 \mathrm{~min}$ ). c Photographic images upon excitation at $365 \mathrm{~nm}$, and $\mathbf{d}$ emission spectra at a concentration of $10^{-2} \mathrm{mg} / \mathrm{mL}$ in deoxygenated toluene under excitation at $365 \mathrm{~nm}$ after depolymerization of the bimetallopolymer $\mathbf{6}$ with CO gas at various time points. e Photographic images and $\mathbf{f}$ emission intensities under deoxygenated conditions after depolymerization of the bimetallopolymer $\mathbf{6}$ with various gases under UV irradiation. ${ }^{1} \%$ ( $/ \mathrm{v}$ ) $\mathrm{H}_{2} \mathrm{~S}$ was present in the $\mathrm{N}_{2}$ gas.

was approximately twice that of $4^{\prime}\left(\Phi_{\mathrm{PL}}=15 \%\right)$. The unique enhancement in phosphorescence of the insulated structure could increase the optical intensity of the output.

A sequential complexation of the insulated monomer 3 with $\mathrm{Pt}$ (II) and $\mathrm{Ru}$ (II) formed the insulated conjugated bimetallopolymer 6, as shown in Fig. 2b. The insulated Pt-acetylide complex $\mathbf{4}$ was co-polymerized with $\mathrm{Ru}(\mathrm{TTP}) \mathrm{CO}$ (5) (TTP: tetratolylporphyrin) to form a one-dimensional coordination polymer $6\left(M_{\mathrm{w}}=1.3 \times\right.$ $\left.10^{5}, M_{\mathrm{n}}=4.5 \times 10^{4}\right)$, as confirmed by size exclusion chromatography (SEC) (The $M_{\mathrm{w}}$ and $M_{\mathrm{n}}$ of polymer $\mathbf{6}$ were obtained by polystylene calibration standard of reaction mixtures.). The carbonyl ligand on the $\mathrm{Ru}(\mathrm{II})$ complex was released as $\mathrm{CO}$ gas upon irradiation with a mercury lamp, affording trans-bispyridyl $\mathrm{Ru}(\mathrm{TTP})^{25}$. Similarly, 3 could be polymerized via sequential complexation with $\mathrm{Ru}(\mathrm{TTP}) \mathrm{CO}$ and then with trans$\left[\mathrm{PtCl}_{2}\left(\mathrm{PEt}_{3}\right)_{2}\right]$ (see Supplementary Information). The sequence of complexation of the metals did not affect the formation of 6 because of the inherent stability of the metal-ligand bond. As a result, the supramolecular structure formed with the PM a-CDs was effectively retained even in the polymeric state. The metal-organic bonds on the bimetallopolymer remained intact even in a coordinating solvent (tetrahydrofuran). The optical behavior of the bimetallopolymer 6 differed significantly from that of Pt-acetylide monomer 4 (Supplementary Figs. 5-7). The excited-state species of $\mathbf{6}$ was quenched via a non-radiative processes on the porphyrin complex. The lifetime of the excitedstate species of $\mathbf{6}$ dramatically decreased to $20 \mathrm{~ns}$ as compared with that of 4 (ref. ${ }^{34}$ ), which was $\sim 1 \mu$ s. Furthermore, the quantum yield of $\mathbf{6}$ decreased to $0.1 \%$ after polymerization, demonstrating the high ET efficiency (>99\%) of the non-radiative pathway. Although several conjugated bimetallopolymers have been reported to date ${ }^{35-41}$, insulated bimetallopolymers bearing rotaxane structures have yet to be reported. Indeed, this is the first report on the synthesis of an insulated conjugated bimetallopolymer with rotaxane structures.

Sigmoidal response by dual self-controlling system. To examine the optical response of the bimetallopolymer, a toluene solution of 6 was reacted with $1 \mathrm{~atm} \mathrm{CO}$ gas at $100^{\circ} \mathrm{C}$ for $20 \mathrm{~min}$. The bimetallopolymer was stable under ambient conditions, while it was prone to reaction with $\mathrm{CO}$ at high temperatures (Supplementary Fig. 9). The strongly coordinating CO molecule generated the $\mathrm{Ru}(\mathrm{TTP}) \mathrm{CO}$ complex (5), subsequently releasing the $\mathrm{Pt}$ complex from it ${ }^{42}$. After the reaction, 6 was depolymerized to 4 and $\mathbf{5}$, as indicated in the SEC profiles (Fig. 3b). While the emission spectrum of $\mathbf{6}$ indicated that the reaction between 4 and the $\mathrm{Ru}$ complex completely quenched the phosphorescence as compared with that of $\mathbf{4}$, the resultant solution displayed yellow phosphorescence that was identical to the phosphorescence of $\mathbf{4}$ when excited at $365 \mathrm{~nm}$ (Fig. 3c and d). This afforded a turn-on optochemical response triggered by CO gas. Additionally, UV irradiation of the depolymerized solution with a mercury lamp for $6 \mathrm{~h}$ resulted in the repolymerization, as confirmed by SEC $\left(M_{\mathrm{w}}=6.9 \times 10^{4}, M_{\mathrm{n}}=2.5 \times 10^{4}\right)$ (Supplementary Fig. 10). The decline in the polymerization degree could be attributed to the slight degradation of the monomer components. Moreover, the bimetallopolymer solution remained intact upon exposure to $1 \mathrm{~atm}$ of various other gases at $100{ }^{\circ} \mathrm{C}$ for $10 \mathrm{~min}$, including oxidative gas $\left(\mathrm{O}_{2}\right)$ and reductive gases $\left(\mathrm{H}_{2}, \mathrm{C}_{2} \mathrm{H}_{4}\right)$, demonstrating its chemospecific reactivity toward $\mathrm{CO}$ gas (Fig. 3e, f, and Supplementary Fig. 11). It was noteworthy that the bimetallopolymer responded to $1 \% \mathrm{CO}$ gas in ambient air to display phosphorescence, while it was intact to ambient air in the absence of CO gas (Supplementary Figs. 12 and 13), indicating that the responsiveness of bimetallopolymer to $\mathrm{CO}$ gas was not affected, even 
a

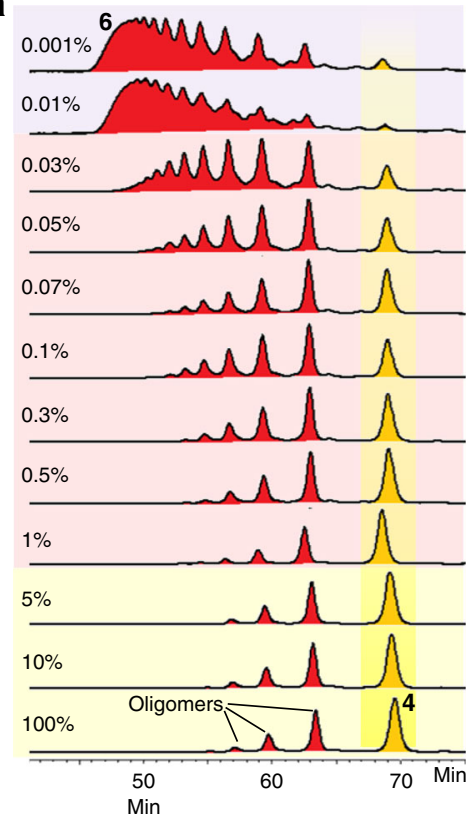

b

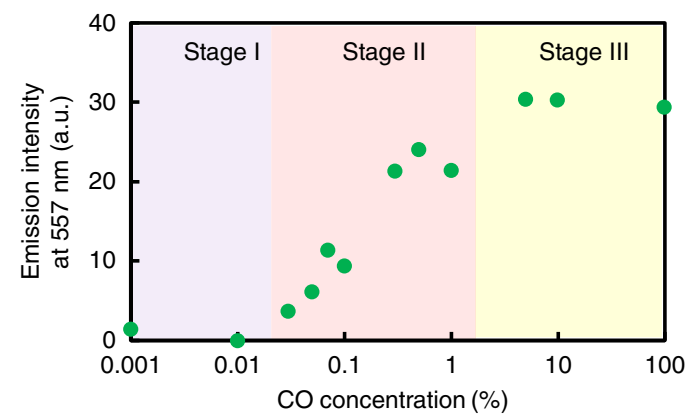

C

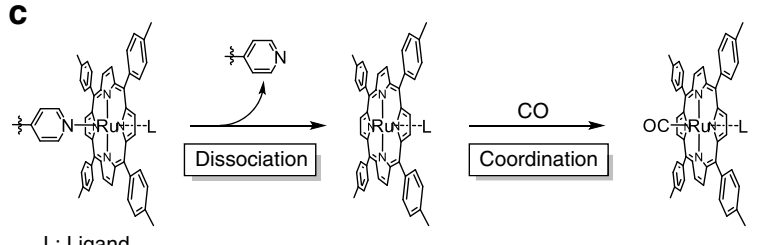

L: Ligand

Fig. 4 Optical output with the dual self-controlling system. a SEC profiles (UV detector, $380 \mathrm{~nm}$ ) and $\mathbf{b}$ concentration dependence of the emission intensities at $557 \mathrm{~nm}$ (deoxygenated condition, excitation at $365 \mathrm{~nm}$ ) after reaction at $100^{\circ} \mathrm{C}$ for 10 min with various concentrations of $\mathrm{CO}$ gas. $\mathbf{c}$ Ligand substitution reaction of the $\mathrm{Ru}(\mathrm{TTP})(\mathrm{L}) \mathrm{Py}$ complex with $\mathrm{CO}$ (Py: pyridine, L: ligand).

under mixed gas conditions. These results supported that the $\mathrm{CO}$ molecule selectively cleaved the Ru-pyridyl bonds on $\mathbf{6}$ without affecting the polymer components. Thus, Ru and Pt took part in imparting chemical reactivity and phosphorescence, respectively, in the optochemical response to $\mathrm{CO}$ gas.

The concentration dependence of the depolymerization of 6 on $\mathrm{CO}$ gas was examined. The phosphorescence intensities were measured after heating a solution of $\mathbf{6}$ in toluene at $100^{\circ} \mathrm{C}$ for 10 min under various concentrations of $\mathrm{CO}$ gas (in $\mathrm{N}_{2}$ ), ranging from 0.001 to $100 \%$. At low concentrations $(<0.01 \%)(0.001 \%$ CO gas in $\mathrm{N}_{2}$ approximately corresponded to 4 equivalents to the $\mathrm{Ru}$ complexes in the solution of bimetallopolymer), the emission was independent of the concentration, although depolymerization still occurred to some extent, as confirmed by SEC analyses (Fig. 4a); however, no emission was obtained (Fig. 4b). In this region (Stage I), the slight depolymerization upon a random cleavage of the $\mathrm{Ru}$ complexes of the polymer only afforded non-radiative bimetallic polymers and oligomers, and not the phosphorescent Pt monomer 4. This was attributed to the effective ET among the adjacent multiple metals, which is a unique feature of bimetallopolymers (Supplementary Figs. 5-7). The independency afforded the first threshold for the gas concentration and prevented the needless responses to trivial inputs. In the next region (Stage II), the luminescent intensity increased with the CO concentration $(0.03-1 \%)$, which was an autonomous response above the threshold (self-activation). On the other hand, at high concentration (5-100\%, Stage III), the emission intensity was again independent of the $\mathrm{CO}$ concentration, affording the second threshold of the output for the gas concentration (Fig. 4b). The second threshold provided a biomimetic automodulation for excess inputs (self-regulation). In the following region, the progress of the reaction was constant when the $\mathrm{CO}$ gas concentration was increased from 5 to $10 \%$ and again to $100 \%$; the same degree of depolymerization was observed by SEC, although the reactions did not reach completion (Fig. 4a). The incomplete depolymerization was also indicated by the lower emission intensity ( 30) as compared with that of the fully converted product $(\sim 60)$ with the same polymer concentration (Fig. 3d). The depolymerizing ligand exchange reaction from $\mathrm{Ru}(\mathrm{TTP})(\mathrm{L}) \mathrm{Py}$ (Py: pyridine, L: ligand) to $\mathrm{Ru}(\mathrm{TTP})(\mathrm{L}) \mathrm{CO}$ proceeded via a two-step dissociation mechanism on the hexacoordinated Ru center (Fig. 4c) ${ }^{26}$. At concentrations below $1 \%$, the rate-determining step of depolymerization was the $\mathrm{CO}$ coordination step. The extent of progress of the reaction gradually increased with the $\mathrm{CO}$ concentration $(0.03-1 \%)$. In contrast, in a CO concentration range of $5-100 \%$, the CO coordination step was sufficiently rapid to not govern the total reaction rate, and hence, the rate-determining step of depolymerization was dissociation of the pyridyl groups; the extent of progress of the reaction was independent of the $\mathrm{CO}$ concentration.

Tunable thresholds for dual self-controlling system. Owing to the two threshold concentrations, the bimetallopolymer displayed a dual self-controlling emission response to the $\mathrm{CO}$ gas concentration (Fig. 5a, b). Furthermore, the thresholds for modulation could be controlled by altering the reaction conditions. For example, the first threshold for activation was controlled by changing the reaction time. In this case, the phosphorescent intensities were measured after heating a solution of the bimetallopolymer in toluene at $100^{\circ} \mathrm{C}$ for $3 \mathrm{~min}$ under various concentrations of $\mathrm{CO}$ gas, ranging from 0.01 to $3 \%$. Above a concentration of $0.1 \%$, the emission intensities increased with the $\mathrm{CO}$ concentration (e.g. Stage II), while below $0.1 \%$, the emission intensities were independent of the CO concentration (Stage I) (Fig. 6a). The second threshold for regulation was controlled by varying the reaction temperature. More specifically, after heating the solution at $90^{\circ} \mathrm{C}$ for $10 \mathrm{~min}$ under various concentrations of $\mathrm{CO}$ gas, ranging from 0.03 to $1 \%$, a decrease in the temperature reduced the rate of the $\mathrm{Ru}$ complex dissociation reaction. Above $0.1 \%$ (Stage III), the emission intensities were constant (Fig. 6b), which demonstrates switching of the ratedetermining step at the threshold. The SEC profiles also supported the trends (Supplementary Fig. 16). Overall, these results confirm that the first and second threshold concentrations could be shifted by altering the reaction time and temperature, respectively. Such separate threshold values for low and high concentrations are common in biological regulatory systems. For example, neurotransmitters, ion channels, and immune systems adjust their responses by promoting and regulating their outputs to external 
a

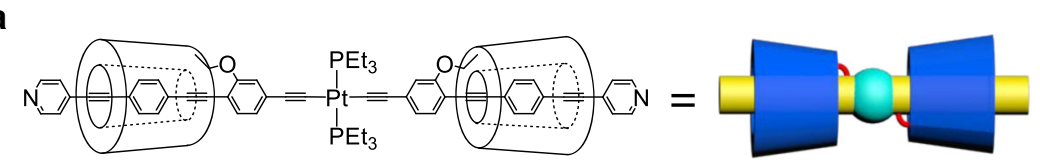

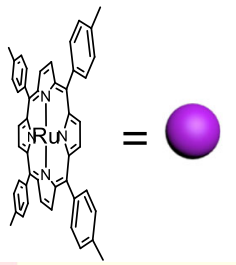

$$
\mathrm{CO}=
$$

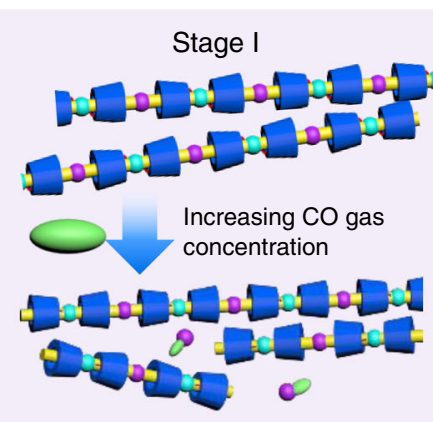

Generation of non-radiative oligomers

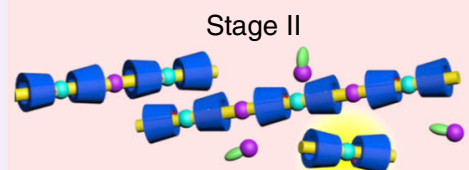

Increasing CO gas concentration

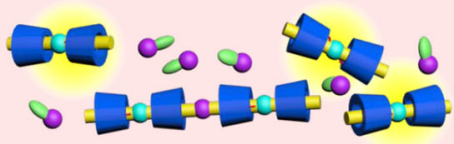

Generation of luminescent Pt-monomer

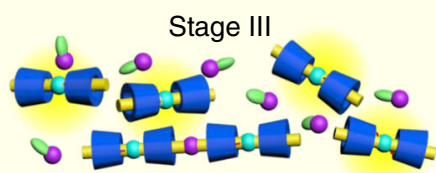

Increasing CO gas concentration

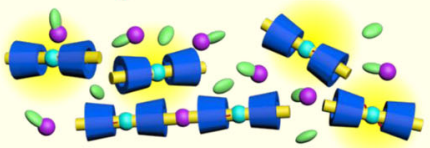

Constant amount of luminescent Pt-monomer

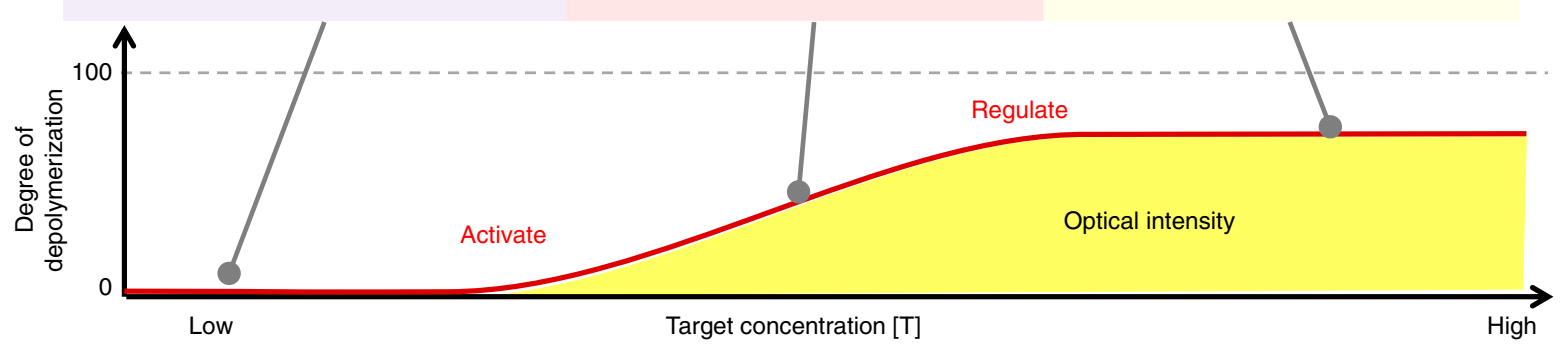

b

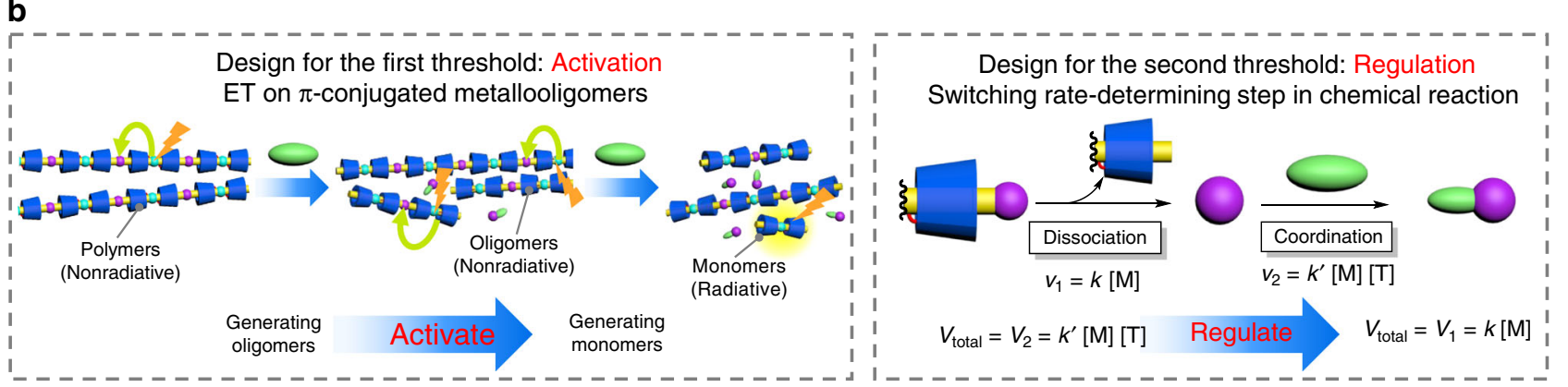

Fig. 5 Summary of the depolymerization steps with two thresholds. a Change in the optical intensity with increasing target concentrations. $\mathbf{b}$ The design principle for self-activation and self-regulation ([M]: concentration of sensing metal, [T]: target concentration, $k$ and $k^{\prime}$ reaction rate constants).
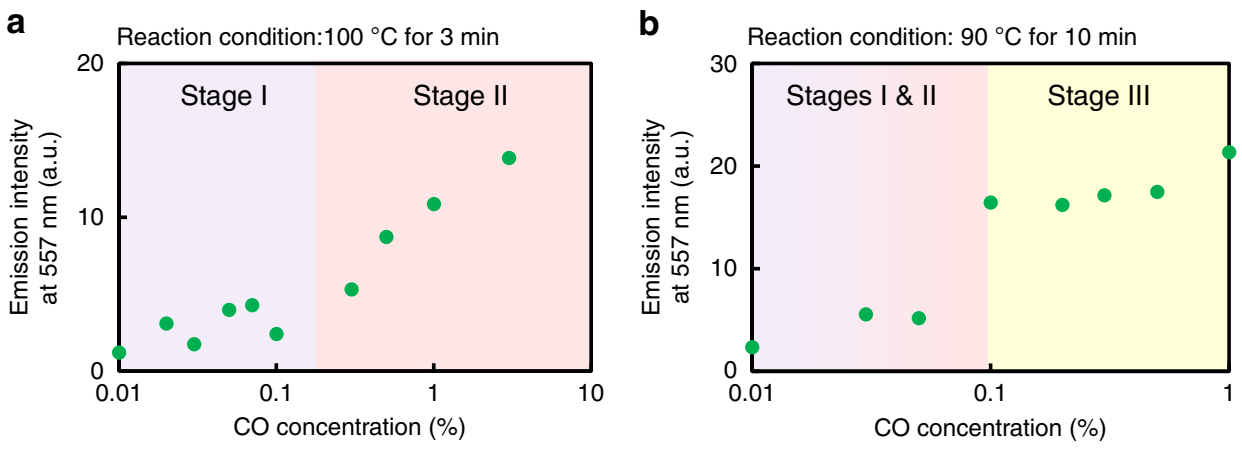

Fig. 6 Tunable thresholds in dual self-controlling system. Concentration dependence of the emission intensities at $557 \mathrm{~nm}$ (deoxygenated condition, excitation at $365 \mathrm{~nm}$ ) after reactions with various concentrations of $\mathrm{CO}$ gas; $\mathbf{a}$ at $100^{\circ} \mathrm{C}$ for $3 \mathrm{~min}$ and $\mathbf{b}$ at $90^{\circ} \mathrm{C}$ for $10 \mathrm{~min}$. 
stimuli as positive aerostatic effects or competitive inhibitions, affording non-linear behaviors. The bimetallopolymer is one such biomimetic material in a single polymer, which was prepared by the precise engineering of artificial molecular systems: the first threshold promoted the phosphorescence output, while the second regulated it, thereby adjusting and prohibiting an excess response.

\section{Discussion}

In summary, the insulated conjugated bimetallopolymer behaved as a self-activating and self-regulating biomimetic material responding to $\mathrm{CO}$ gas by exhibiting unusual, distinct signal changes at two threshold concentrations. The self-activation was driven by ET after excitation of the $\pi$-conjugated bimetallopolymer and oligomers, affording the first threshold via monomer-induced emission. In contrast, the self-regulation was driven by dissociative ligand substitution on the reactive metal complex, affording the second threshold via a switch in the rate-determining step. We expect that the incorporation of other metal complexes in this strategy could enable control of the response temperature, the target gases, and the concentration range, thereby provide further diversity on terms of the responses and the operating environment for such biomimetic materials. The strategies for incorporating multiple self-modulating systems into irreversible reactions would provide novel molecular designs for controlling the detection, manufacturing, and transferring of chemicals. Such biomimetic controlling would also lead to unprecedented systems in diverse areas of materials chemistry, e.g., autonomous modulation, to automatically tune the outputs depending on the external environment without any requirement for human control.

\section{Methods}

Synthesis of 4. Under argon, $3(133 \mathrm{mg}, 88.0 \mu \mathrm{mol})$, trans $-\mathrm{PtCl}_{2}\left(\mathrm{PEt}_{3}\right)_{2}(21.5 \mathrm{mg}$, $42.8 \mu \mathrm{mol})$, and $\mathrm{CuI}(1.9 \mathrm{mg}, 10 \mu \mathrm{mol})$ were dissolved in degassed piperidine $(5 \mathrm{~mL})$. The reaction mixture was stirred at room temperature for $2 \mathrm{~h}$. The mixture was quenched with aqueous $\mathrm{NH}_{4} \mathrm{Cl}$ and diluted with $\mathrm{CHCl}_{3}$. The organic layer was separated and dried over $\mathrm{MgSO}_{4}$, and then filtered. The solvent was removed by evaporation, and the residue was purified by GPC with $\mathrm{CHCl}_{3}$ as the eluent to yield 4 as a yellow solid $(102 \mathrm{mg}, 70 \%)$. MALDI TOF-MS: $(\mathrm{m} / z) 3475.4682\left(\left[\mathrm{M}+\mathrm{Na}^{+}\right]^{+}\right.$, $\mathrm{C}_{164} \mathrm{H}_{238} \mathrm{~N}_{2} \mathrm{O}_{60} \mathrm{P}_{2} \mathrm{PtNa}$, calcd. 3475.4661). ${ }^{1} \mathrm{H}$ NMR $\left(500 \mathrm{MHz}, \mathrm{CDCl}_{3}\right.$, r.t.) $\delta 8.64$ (br, $4 \mathrm{H}, \mathrm{PyH}), 8.08$ (d, $J=8.2 \mathrm{~Hz}, 4 \mathrm{H}, \mathrm{ArH}), 7.63(\mathrm{~d}, J=7.9 \mathrm{~Hz}, 4 \mathrm{H}, \mathrm{ArH}), 7.34$ (br, $4 \mathrm{H}$, $\mathrm{PyH}), 7.30$ (d, $J=7.9 \mathrm{~Hz}, 2 \mathrm{H}, \mathrm{ArH}), 7.02(\mathrm{~d}, J=8.2 \mathrm{~Hz}, 2 \mathrm{H}, \mathrm{ArH}), 7.00$ (s, 2H, ArH), 5.11-2.85 (m, 186H, CD-H, $\left.\mathrm{OCH}_{3}\right), 2.17-2.15\left(\mathrm{~m}, 12 \mathrm{H}, \mathrm{PCH}_{2}\right), 1.26-1.19(\mathrm{~m}, 18 \mathrm{H}$, $\left.\mathrm{PCH}_{2} \mathrm{CH}_{3}\right) .{ }^{13} \mathrm{C} \mathrm{NMR}\left(126 \mathrm{MHz}, \mathrm{CDCl}_{3}\right.$, r.t.): $\delta 161.81,149.83,132.90,132.43$, $131.53,131.13,131.01,125.93,125.60$ (peaks overlapped), 124.08, 123.61, 122.32, $112.95,109.51,100.80,100.45,100.21,100.09,100.01,98.13,93.71,93.01,90.03,88.25$, $83.83,82.78,82.60$ (peaks overlapped), $82.55,82.40,82.21,82.18$ (peaks overlapped), $82.14,82.02,81.70,81.48,81.29$ (peaks overlapped), 81.22, 81.18, 81.07, 76.22, 72.25, $71.94,71.72,71.55$ (peaks overlapped), 71.28 (peaks overlapped), 71.17, 71.08, 70.72, $70.15,61.94,61.82$ (peaks overlapped), 61.74, 61.71, 61.58, 59.05 (peaks overlapped), $58.96,58.67,58.64,58.40,58.05,57.89,57.76,57.69,57.56,16.45\left(\mathrm{t},{ }^{1} J_{\mathrm{C}-\mathrm{P}}=35.2 \mathrm{~Hz}\right)$, 8.31. ${ }^{31} \mathrm{P}\left\{{ }^{1} \mathrm{H}\right\} \mathrm{NMR}\left(160 \mathrm{MHz}, \mathrm{CDCl}_{3}\right.$, r.t.): $\delta 11.17\left(\mathrm{~s}+\mathrm{d},{ }^{1} J_{\mathrm{P}-\mathrm{Pt}}=2353 \mathrm{~Hz}\right)$.

Synthesis of $4^{\prime}$. Under argon, $3(80 \mathrm{mg}, 53 \mu \mathrm{mol})$ was dissolved in degassed tetrahydrofuran $(5 \mathrm{~mL})$. The solution was stirred at $60^{\circ} \mathrm{C}$ overnight. The solvent was removed by evaporation to yield $\mathbf{3}^{\prime}$ as a yellow solid ( $80 \mathrm{mg}$, quant.) without further purification. Under argon, 3' $(50 \mathrm{mg}, 33 \mu \mathrm{mol})$ and trans $-\mathrm{PtCl}_{2}\left(\mathrm{PEt}_{3}\right)_{2}$ $(7.9 \mathrm{mg}, 16 \mu \mathrm{mol})$ and $\mathrm{CuI}(0.6 \mathrm{mg}, 3 \mu \mathrm{mol})$ were dissolved in degassed piperidine $(3 \mathrm{~mL})$. The reaction mixture was stirred at room temperature for $4 \mathrm{~h}$. The mixture was quenched with aqueous $\mathrm{NH}_{4} \mathrm{Cl}$ and diluted with $\mathrm{CHCl}_{3}$. The organic layer was separated and dried over $\mathrm{MgSO}_{4}$, and then filtered. The solvent was removed by evaporation, and the residue was purified by $\mathrm{GPC}$ with $\mathrm{CHCl}_{3}$ as the eluent to yield $\mathbf{4}^{\prime}$ as a yellow solid (27 mg, 47\%). MALDI TOF-MS: $(\mathrm{m} / \mathrm{z}) 3475.4659\left(\left[\mathrm{M}+\mathrm{Na}^{+}\right]^{+}\right.$, $\mathrm{C}_{164} \mathrm{H}_{238} \mathrm{~N}_{2} \mathrm{O}_{60} \mathrm{P}_{2} \mathrm{PtNa}$, calcd. 3475.4661). ${ }^{1} \mathrm{H}$ NMR (500 MHz, $\mathrm{CDCl}_{3}$, r.t.): $\delta 8.77$ (br, $4 \mathrm{H}, \mathrm{PyH}), 7.63$ (d, $J=8.2 \mathrm{~Hz}, 4 \mathrm{H}, \mathrm{ArH}), 7.50$ (d, $J=8.2 \mathrm{~Hz}, 4 \mathrm{H}, \mathrm{ArH}), 7.47$ (br, $4 \mathrm{H}, \mathrm{PyH}), 7.29$ (d, J=7.9 Hz, 2H, ArH), $6.85(\mathrm{~d}, J=7.9 \mathrm{~Hz}, 2 \mathrm{H}, \mathrm{ArH}), 6.76$ (s, $2 \mathrm{H}, \mathrm{ArH}), 5.22-3.02\left(\mathrm{~m}, 186 \mathrm{H}, \mathrm{CD}-\mathrm{H}, \mathrm{OCH}_{3}\right), 2.13-2.12\left(\mathrm{~m}, 12 \mathrm{H}, \mathrm{PCH}_{2}\right)$, $1.23-1.17\left(\mathrm{~m}, 18 \mathrm{H}, \mathrm{PCH}_{2} \mathrm{CH}_{3}\right) .{ }^{13} \mathrm{C} \mathrm{NMR}\left(126 \mathrm{MHz} \mathrm{CDCl}_{3}\right.$, r.t.): $\delta 159.11,149.70$, $132.71,131.73,131.60,131.23,130.45,124.76,124.04,121.22,113.92,111.35$, $111.23,110.32,109.65,100.68,100.24,100.17,100.14,100.10,99.42,93.82,93.55$, $89.62,88.22,82.69,82.59,82.52$ (peaks overlapped), 82.49, 82.33, 82.30, 82.24, $82.20,82.18,82.08,81.58,81.23$ (peaks overlapped), 81.19 (peaks overlapped), $81.11,71.92,71.78,71.58$ (peaks overlapped), 71.55, 71.47, 71.30 (peaks overlapped), 71.18 (peaks overlapped), 70.96, 67.51, 61.86, 61.83 (peaks overlapped),
61.81, 61.79, 61.76, 59.15 (peaks overlapped), 59.07, 59.03 (peaks overlapped), $58.37,57.93,57.90$ (peaks overlapped), 57.83, 57.35, 16.38, (t, $\left.{ }^{1} J_{\mathrm{C}-\mathrm{P}}=33.9 \mathrm{~Hz}\right)$, 8.37. ${ }^{31} \mathrm{P} \mathrm{NMR}\left(202 \mathrm{MHz}, \mathrm{CDCl}_{3}\right.$, r.t.): $\delta 11.56\left(\mathrm{~s}+\mathrm{d},{ }^{1} J_{\mathrm{P}-\mathrm{Pt}}=2365 \mathrm{~Hz}\right)$.

Synthesis of 6 . Compound 4 (20 mg, $5.8 \mu \mathrm{mol})$ and [Ru(TTP)CO] (5: $4.9 \mathrm{mg}$, $5.8 \mu \mathrm{mol})$ were dissolved in toluene $(20 \mathrm{~mL})$. The reaction mixture was irradiated using a high-pressure mercury lamp for $8 \mathrm{~h}$ under argon bubbling and stirring at room temperature. As the reaction was proceeded, the solution color was changed from red to purple. The solvent was removed by evaporation to yield $\mathbf{6}$ as a purple solid. The bimetallopolymer was used for the following experiments without further purifications $\left(0.2 \mathrm{mg}: M_{\mathrm{w}}=1.3 \times 10^{5}, M_{\mathrm{n}}=4.5 \times 10^{4}\right)$. ${ }^{1} \mathrm{H}$ NMR $(500 \mathrm{MHz}$, $\mathrm{CDCl}_{3}$, r.t.): $\delta 8.16$ (br, $\left.8 \mathrm{H}, \beta-\mathrm{H}\right), 7.89$ (br, $12 \mathrm{H}$, tol-H, ArH), 7.44 (br, 10H, tol-H, ArH), 7.25-7.10 (br, 4H, ArH), 6.93 (br, 4H, ArH), 5.29 (br, 4H, PyH), 5.04-2.77 (m, 186H, CD-H), 2.62 (br s, 12H, tol- $\mathrm{CH}_{3}$ ), 2.25 (br, 4H, PyH), 2.10-2.08 (br m, $12 \mathrm{H}, \mathrm{PCH}_{2}$ ), 1.17-1.15 (br m, $\left.18 \mathrm{H}, \mathrm{PCH}_{2} \mathrm{CH}_{3}\right) .{ }^{31} \mathrm{P} \mathrm{NMR}\left(202 \mathrm{MHz}, \mathrm{CDCl}_{3}\right.$, r.t.): $\delta$ $11.20\left(\mathrm{~s}+\mathrm{d},{ }^{1} J_{\mathrm{P}-\mathrm{Pt}}=2359 \mathrm{~Hz}\right)$.

General procedure of reaction of bimetallopolymer 6 with $\mathrm{CO}$ gas. Bimetallopolymer $6(0.2 \mathrm{mg})$ was added into a 20 - $\mathrm{mL}$ two-necked round-bottom flask (40 mL total volume). The flask was filled with $\mathrm{CO}$ gas and then was added toluene $(1 \mathrm{~mL})$. The mixture was stirred at $100^{\circ} \mathrm{C}$ for $20 \mathrm{~min}$. As the reaction was proceeded, the solution color changed from purple to red. The reaction was monitored by analytical SEC chromatogram to confirm the decomplexation of bimetallopolymer.

Recycling procedure. Bimetallopolymer $6\left(0.2 \mathrm{mg}: M_{\mathrm{w}}=1.3 \times 10^{5}, M_{\mathrm{n}}=4.5 \times\right.$ $10^{4}$ ) was added into a $20-\mathrm{mL}$ two-necked round-bottom flask ( $40 \mathrm{~mL}$ total volume). The flask was filled with $\mathrm{CO}$ gas and then was added toluene $(1 \mathrm{~mL})$. The mixture was stirred at $100{ }^{\circ} \mathrm{C}$ for $20 \mathrm{~min}$. The reaction was monitored by analytical SEC chromatogram to confirm the decomplexation of bimetallopolymer. After the depolymerization, the resultant mixture without any purification was irradiated using a mercury lamp for $1.5 \mathrm{~h}$ under $\mathrm{N}_{2}$ bubbling and stirring at room tem perature to change the solution color from red to purple. The reaction was monitored by analysis SEC chromatogram to confirm the recomplexation to form bimetallopolymer $\left(M_{\mathrm{w}}=6.9 \times 10^{4}, M_{\mathrm{n}}=2.5 \times 10^{4}\right)$.

Procedure of reactions with various gases. Bimetallopolymer $6(0.2 \mathrm{mg})$ was added into a 20 - $\mathrm{mL}$ two-necked round-bottom flask ( $40 \mathrm{~mL}$ total volume). The flask was filled with target gas $\left(\mathrm{N}_{2}, \mathrm{O}_{2}, \mathrm{H}_{2}, \mathrm{CO}_{2}, \mathrm{CO}, \mathrm{CH}_{4}, \mathrm{C}_{2} \mathrm{H}_{4}\right.$, and $1 \% \mathrm{v} / \mathrm{v} \mathrm{H}_{2} \mathrm{~S}$ in $\mathrm{N}_{2}$ gases) and then was added toluene $(0.5 \mathrm{~mL})$. The solution was stirred at $100{ }^{\circ} \mathrm{C}$ for $10 \mathrm{~min}$. The flask was immediately cooled to room temperature to prohibit the reaction.

Procedure of analyses for concentration dependence. Bimetallopolymer 6 $(0.2 \mathrm{mg})$ was added into a $20-\mathrm{mL}$ two-necked round-bottom flask $(40 \mathrm{~mL}$ total volume). The flask was filled with $\mathrm{N}_{2}$ gas and then was added toluene $(0.5 \mathrm{~mL})$. CO (>99.95\%) gas was added into the flask to provide the desired concentrations. The solutions were stirred at $100^{\circ} \mathrm{C}$ for $10 \mathrm{~min}$. The flask was immediately cooled to room temperature to prohibit the $\mathrm{CO}$ gas reaction. The emission spectra were measured under nitrogen atmosphere, after excluding the reaction gas.

\section{Data availability}

All other data that support the findings of this study are available within the article and its Supplementary Information, or from the corresponding author upon reasonable request.

Received: 21 August 2019; Accepted: 27 December 2019; Published online: 21 January 2020

\section{References}

1. Dokholyan, N. V. Controlling allosteric networks in proteins. Chem. Rev. 116, 6463-6487 (2016)

2. Changeux, J.-P. Allosteric mechanisms of signal transduction. Science $\mathbf{3 0 8}$, 1424-1428 (2005)

3. Wang, F., Lu, C. H. \& Willner, I. From cascaded catalytic nucleic acids to enzyme-DNA nanostructures: controlling reactivity, sensing, logic operations, and assembly of complex structures. Chem. Rev. 114, 2881-2941 (2014).

4. Kavalali, E. T. The mechanisms and functions of spontaneous neurotransmitter release. Nat. Rev. Neurosci. 16, 5-16 (2015).

5. Catterall, W. A., Wisedchaisri, G. \& Zheng, N. The chemical basis for electrical signaling. Nat. Chem. Biol. 13, 455-463 (2017).

6. Levine, M. V., Cuendet, M. A., Khelashvili, G. \& Weinstein, H. Allosteric mechanisms of molecular machines at the membrane: transport by sodiumcoupled symporters. Chem. Rev. 116, 6552-6587 (2016). 
7. Wang, L. et al. Boronic acid: a bio-inspired strategy to increase the sensitivity and selectivity of fluorescent NADH probe. J. Am. Chem. Soc. 138, 10394-10397 (2016).

8. Riddell, I. A. et al. Anion-induced reconstitution of a self-assembling system to express a chloride-binding Co 10 L 15 pentagonal prism. Nat. Chem. 4 751-756 (2012).

9. Yuasa, J. \& Fukuzumi, S. An OFF-OFF-ON fluorescence sensor for metal ions in stepwise complex formation of 2,3,5,6-tetrakis(2-pyridyl)pyrazine with metal ions. J. Am. Chem. Soc. 128, 15976-15977 (2006).

10. Imai, Y., Kawai, T. \& Yuasa, J. OFF-ON-OFF dual emission at visible and UV wavelengths from carbazole functionalized $\beta$-diketonate europium(III) complex. J. Phys. Chem. A 120, 4131-4138 (2016).

11. Dong, Z., Luo, Q. \& Liu, J. Artificial enzymes based on supramolecular scaffolds. Chem. Soc. Rev. 41, 7890-7908 (2012).

12. Chen, X. et al. DCEO biotechnology: tools to design, construct, evaluate, and optimize the metabolic pathway for biosynthesis of chemicals. Chem. Rev. 118, 4-72 (2018).

13. Azzaroni, O. et al. Mechanically induced generation of counterions inside surface-grafted charged macromolecular films: towards enhanced mechanotransduction in artificial systems. Angew. Chem. Int. Ed. 45, 7440-7443 (2006).

14. Guix, M., Mayorga-Martinez, C. C. \& Merkoçi, A. Nano/micromotors in (bio) chemical science applications. Chem. Rev. 114, 6285-6322 (2014).

15. Zhang, L., Marcos, V. \& Leigh, D. A. Molecular machines with bio-inspired mechanisms. Proc. Natl Acad. Sci. USA 115, 9397-9404 (2018).

16. Erbas-Cakmak, S., Leigh, D. A., McTernan, C. T. \& Nussbaumer, A. L. Artificial molecular machines. Chem. Rev. 115, 10081-10206 (2015).

17. Lo, K. K.-W. \& Li, S. P.-Y. Utilization of the photophysical and photochemical properties of phosphorescent transition metal complexes in the development of photofunctional cellular sensors, imaging reagents, and cytotoxic agents. RSC Adv. 4, 10560-10585 (2014).

18. Xiang, H., Cheng, J., Ma, X., Zhou, X. \& Chruma, J. J. Near-infrared phosphorescence: materials and applications. Chem. Soc. Rev. 42, 6128-6185 (2013).

19. Ma, D.-L. et al. Recent advances in luminescent heavy metal complexes for sensing. Coord. Chem. Rev. 256, 3087-3113 (2012).

20. Wong, W. Y. \& Harvey, P. D. Recent progress on the photonic properties of conjugated organometallic polymers built upon the trans-Bis (paraethynylbenzene)bis(phosphine)platinum(II) chromophore and related derivatives. Macromol. Rapid Commun. 31, 671-713 (2010).

21. Barigelletti, F. \& Flamigni, L. Photoactive molecular wires based on metal complexes. Chem. Soc. Rev. 29, 1-12 (2000).

22. Keefe, M. Luminescent sensor molecules based on coordinated metals: a review of recent developments. Coord. Chem. Rev. 205, 201-228 (2000).

23. Ogawa, K., Guo, F. \& Schanze, K. S. Phosphorescence quenching of a platinum acetylide polymer by transition metal ions. J. Photochem. Photobiol. A Chem. 207, 79-85 (2009).

24. Masai, H. et al. Enhancement of phosphorescence and unimolecular behavior in the solid state by perfect insulation of platinum-acetylide polymers. J. Am. Chem. Soc. 136, 14714-14717 (2014).

25. Masai, H. et al. Synthesis of one-dimensional metal-containing insulated molecular wire with versatile properties directed toward molecular electronics materials. J. Am. Chem. Soc. 136, 1742-1745 (2014).

26. Paulson, D. R. et al. The reaction of ruthenium (II) octaethylporphyrin and ruthenium (II) tetraphenylporphyrin complexes with carbon monoxide. Inorg. Chim. Acta 151, 149-152 (1988).

27. Frampton, M. \& Anderson, H. Insulated molecular wires. Angew. Chem. Int. Ed. 46, 1028-1064 (2007).

28. Masai, H. \& Terao, J. Stimuli-responsive functionalized insulated conjugated polymers. Polym. J. 49, 805-814 (2017).

29. Masai, H., Terao, J., Fujihara, T. \& Tsuji, Y. Rational design for rotaxane synthesis through intramolecular slippage: control of activation energy by rigid axle length. Chem. Eur. J. 22, 6624-6630 (2016).

30. Long, N. J. \& Williams, C. K. Metal alkynyl $\sigma$ complexes: synthesis and materials. Angew. Chem. Int. Ed. 42, 2586-2617 (2003).

31. Terao, J., Masai, H., Fujihara, T. \& Tsuji, Y. Synthesis of insulated Pt-alkynyl complex polymer. Chem. Lett. 41, 652-653 (2012).

32. Ohshiro, N., Takei, F., Onitsuka, K. \& Takahashi, S. Synthesis of organometallic dendrimers with a backbone composed of platinum-acetylide units. J. Organomet. Chem. 569, 195-202 (1998).

33. Kiguchi, M. et al. Single-molecule conductance of $\pi$-conjugated rotaxane: new method for measuring stipulated electric conductance of $\pi$-conjugated molecular wire using STM break junction. Small 8, 726-730 (2012).

34. Tachibana, Y., Moser, J. E., Grätzel, M., Klug, D. R. \& Durrant, J. R. Subpicosecond interfacial charge separation in dye-sensitized nanocrystalline titanium dioxide films. J. Phys. Chem. 100, 20056-20062 (1996).
35. Lavastre, O., Even, M., Dixneuf, P. H., Pacreau, A. \& Vairon, J.-P. Novel ruthenium- or iron-containing tetraynes as precursors of mixed-metal oligomers. Organometallics 15, 1530-1531 (1996).

36. Ho, C.-L. \& Wong, W.-Y. Charge and energy transfers in functional metallophosphors and metallopolyynes. Coord. Chem. Rev. 257, 1614-1649 (2013).

37. Vicente, J., Chicote, M.-T., Alvarez-Falcón, M. M. \& Jones, P. G. Platinum(II) and mixed platinum(II)/gold(I) $\sigma$-alkynyl complexes. The first anionic $\sigma$ alkynyl metal polymers. Organometallics 24, 2764-2772 (2005).

38. Higuchi, M. Stimuli-responsive metallo-supramolecular polymer films: design, synthesis and device fabrication. J. Mater. Chem. C 2, 9331-9341 (2014)

39. Zhou, G.-J. \& Wong, W.-Y. Organometallic acetylides of $\mathrm{Pt}^{\mathrm{II}}, \mathrm{Au}^{\mathrm{I}}$ and $\mathrm{Hg}^{\mathrm{II}}$ as new generation optical power limiting materials. Chem. Soc. Rev. 40, 2541-2566 (2011).

40. Zhou, G. et al. Electrophosphorescent heterobimetallic oligometallaynes and their applications in solution-processed organic light-emitting devices. Chem. Asian J. 5, 2405-2414 (2010).

41. Yuan, M., Wang, F. \& Tian, Y.-K. Metallo-supramolecular polymers derived from benzothiadiazole-based platinum acetylide complexes for fluorescent security application. RSC Adv. 8, 40794-40797 (2018).

42. Barley, M. H., Dolphin, D. \& James, B. R. Reversible intramolecular electron transfer within a ruthenium(III) porphyrin-ruthenium(II) porphyrin $\pi$-cation radical system induced by changes in axial ligation. J. Chem. Soc. Chem. Commun. 1499-1500 (1984).

\section{Acknowledgements}

The authors appreciate Prof. Dr. Masaru Ogura and Dr. Takahiko Moteki for their helpful access and advice on thermogravimetry measurements. This research was supported by financial support (JST CREST Grant Number JPMJCR1331 and JPMJCR1912, Environment Research and Technology Development Fund of the ERCA Japan Grant Number 5RF-1802, JSPS KAKENHI Grant Numbers 18H05158, 19H02696, and 19K15629, Asahi Glass Foundation, The Amada Foundation, Izumi Science and Technology Foundation, Yashima Environment Technology Foundation, and Iketani Science and Technology Foundation).

\section{Author contributions}

H.M. and J.T. designed and directed the project. T.Y. performed the synthetic experiments and collected the central data. T.Y. and H.V.M. investigated the self-controlling system. M.L. and Y.Ta. performed and interpreted the optical analyses. T.F. and Y.Tsu. discussed the results. H.M. wrote the manuscript. All authors have approved the manuscript.

\section{Competing interests}

The authors declare no competing interests.

\section{Additional information}

Supplementary information is available for this paper at https://doi.org/10.1038/s41467019-14271-2.

Correspondence and requests for materials should be addressed to J.T.

Peer review information Nature Communications thanks Ho Yu Au-Yeung, Ying-Wei Yang, and other anonymous reviewers for their contributions to the peer review of this work.

Reprints and permission information is available at http://www.nature.com/reprints

Publisher's note Springer Nature remains neutral with regard to jurisdictional claims in published maps and institutional affiliations.

Open Access This article is licensed under a Creative Commons Attribution 4.0 International License, which permits use, sharing, adaptation, distribution and reproduction in any medium or format, as long as you give appropriate credit to the original author(s) and the source, provide a link to the Creative Commons license, and indicate if changes were made. The images or other third party material in this article are included in the article's Creative Commons license, unless indicated otherwise in a credit line to the material. If material is not included in the article's Creative Commons license and your intended use is not permitted by statutory regulation or exceeds the permitted use, you will need to obtain permission directly from the copyright holder. To view a copy of this license, visit http://creativecommons.org/ licenses/by/4.0/.

(C) The Author(s) 2020 